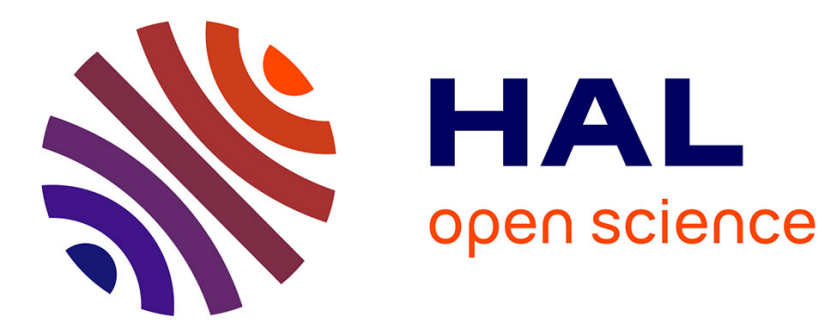

\title{
Applying Weigh-in-motion traffic data to reliability based assessment of bridge structures
}

Xiao Yi Zhou, Franziska Schmidt, François Toutlemonde, Bernard Jacob

\section{To cite this version:}

Xiao Yi Zhou, Franziska Schmidt, François Toutlemonde, Bernard Jacob. Applying Weigh-in-motion traffic data to reliability based assessment of bridge structures. ICOSSAR2013, 11th International Conference on Structural Safety \& Reliability, Jun 2013, France. 8p. hal-00949752

\section{HAL Id: hal-00949752 https://hal.science/hal-00949752}

Submitted on 20 Feb 2014

HAL is a multi-disciplinary open access archive for the deposit and dissemination of scientific research documents, whether they are published or not. The documents may come from teaching and research institutions in France or abroad, or from public or private research centers.
L'archive ouverte pluridisciplinaire HAL, est destinée au dépôt et à la diffusion de documents scientifiques de niveau recherche, publiés ou non, émanant des établissements d'enseignement et de recherche français ou étrangers, des laboratoires publics ou privés. 


\title{
Applying weigh-in-motion traffic data to reliability based assessment of bridge structures
}

\author{
X. Zhou, F. Schmidt, F. Toutlemonde \& B. Jacob \\ French Institute of Sciences and Technologies for Transportation, Development and Networks (IFSTTAR), \\ France
}

\begin{abstract}
The knowledge of the process of the deterioration of structural resistance is crucial for existing bridge assessment. However, precisely modeling the process of loading also affects the evaluation. Indeed traffic loading is one of the main loads that a bridge is subjected to in its service time. This paper investigates the role of traffic loading on the time-dependent reliability of a given bridge. Emphasis is placed on updating traffic load effect models with consideration of traffic evolution due to traffic growth, change of traffic composition and modification of the weight limit regulation. Moreover, loss of resistance due to chloride induced corrosion is taken in account. Finally, the annual reliability is evaluated to quantify the influence of traffic evolution on the reliability of a reinforced concrete bridge.
\end{abstract}

\section{INTRODUCTION}

A considerable effort has been recently devoted to assessment of existing bridges. Short- to mediumspan bridges are the main concern as a majority of bridges are of this type. For example in France, the spans of $85 \%$ of bridges in the national road network are less than $50 \mathrm{~m}$ (Cremona, 2011). Studies have shown that this type of bridge may be significantly governed by traffic loading (Bakht \& Jaeger, 1987). However, the traffic is increasing due to the growth of economy. In Europe, the road freight transport has increased by 35\% between 1995 and 2010 (European Commission, 2012), and this increasing trend is projected to keep on with a ratio of about $1.7 \%$ per year till 2030 (European Commission, 2008). It is thus important to evaluate the impact of this increase on existing short- to medium-span bridge infrastructures.

On the other side, reliability based assessment is a useful tool to evaluate the condition of a bridge as it considers the uncertainty in bridge resistance and its loading (Melchers, 1987). For an existing bridge, the primary is to evaluate its status as accurately as possible for constituting intervention strategy to cater for the increasing demand of traffic. Current experimental results in Du et al. (2013) have indicated that the deflections of test beams are bigger when they are subjected simultaneously to loading and reinforcement corrosion than when this processes are applied separately. Therefore, it is important to update the resistance, $R(t)$, and the load effect model
$S(t)$ with time to consider time-dependent probability of failure:

$$
p_{f}(t)=\operatorname{Pr}[R(t)<S(t)]
$$

In recent years, a lot of work has been done to improve the accuracy of site-specific reliability assessment of bridges (Bailey \& Bez, 1999, Jacob et al. 1989, Flint \& Jacob, 1996). Weigh-in-motion (WIM) systems have been more and more frequently used to collect data for site-specific traffic data in order to model accurately the traffic load that the considered bridge experienced. On the other hand, material deterioration process has been considered to model the degradation of structural resistance (Stewart \& Rosowsky, 1998).

This paper presents the application of measured WIM traffic data to reliability based site-specific safety assessment of bridge structures. For illustrative purpose, the time-dependent analysis is applied to a typical reinforced concrete bridge. The deterioration of the structural resistance of the bridge due to the loss of area of reinforcing steel through corrosion is taken in account. A set of 6 months traffic data collected using a French WIM system, which is representative of high quality modern WIM systems, has been used. Emphasis is placed on investigating the influence of traffic evolution on modeling traffic load effects. To extend the available traffic data, a Monte Carlo simulation method was used to generate traffic with mathematical models modeling traffic, developed from WIM measurements. The effects 
caused by the passage of the traffic loads can be easily calculated by combination with influence lines or surfaces of the load effect of interest. Then the lifetime maximum distribution of the effects can be studied using extreme value analysis.

The paper is organized as follows: Section 2 introduces the resistance loss model for reinforced concrete beam. A detailed traffic load effect modeling method with consideration of traffic evolution is presented in Section 3. Section 4 illustrates the influence of traffic evolution on bridges with an example. Conclusion is drawn in Section 5.

\section{CAPACITY LOSS DUE TO CHLORIDE INDUCED CORROSION}

During service time, the resistance of the structure of the bridge may degrade due to many factors, like environmental aggression, cracking, fatigue damage etc. For reinforced concrete bridge structures, the resistance degradations are mainly due to reinforcing steel corrosion and concrete cracking. Chloride concentration and carbonation are two main factors inducing reinforcing steel corrosion. In this article we deal only with the degradation induced by chloride aggression as major failure mode of $\mathrm{RC}$ bridges for which steel reinforcement corrosion is due to deicing salt (Weyers et al. 1994). The degradation of resistance is commonly assessed through the reduction of the tensile reinforcement area, $A_{s}$, and the area in age, $t$, is estimated to be:

$$
A_{s}(t)=\left\{\begin{array}{cc}
\frac{\pi}{4} d_{0}^{2} & t<T_{i} \\
\frac{\pi}{4}\left[d_{0}-2 \lambda\left(t-T_{i}\right)\right]^{2} & t \geq T_{i}
\end{array}\right.
$$

Where $d_{0}$ is the initial diameter of the reinforcing bar, $T_{i}$ is the time of initiation of reinforcing bar corrosion, and $\lambda \approx 0.0116 R \cdot i_{\text {corr }}$ is the corrosion rate in $\mathrm{mm} / \mathrm{yr}$, where $i_{\text {corr }}$ is current density, and $R$ is a factor that includes the effect of highly localized pitting normally associated with chloride contamination. The initiation time is then given by:

$T_{i}=\frac{c_{p}}{4 D_{0}}\left[\operatorname{erf}^{-1}\left(\frac{C_{0}-C_{c r}}{C_{0}}\right)\right]^{-2}$

Where $c_{p}$ is the concrete cover depth $(\mathrm{cm}), D_{0}$ is diffusion coefficient, $C_{0}$ is the equilibrium chloride concentration at the concrete surface (in percentage of the cement weight), $C_{c r}$ is the threshold chloride concentration at which corrosion begins (in percentage of cement weight), where chlorides have passed through concrete cover, and $\operatorname{erf}^{l}(\cdot)$ is the inverse error function.

\section{TRAFFIC LOAD EFFECTS MODELING}

\subsection{WIM data and traffic load effects calculation}

Traffic data, taken from a piezo-ceramic weigh-inmotion (WIM) system on the A9 motorway near Saint Jean de Vedas, in South-Eastern France, was used to establish the traffic load effect model for the reliability analysis. Weights and dimensions were collected for trucks travelling in the slow and fast lanes in one direction of the 6-lane motorway from January 2010 to May 2010. 581011 trucks in 86 days were drawn from the original data by excluding obvious false recordings, weekends and system inactivity days. The histogram of gross vehicle weight of the remaining traffic is presented in Figure 1: Two modes are present, but the most important one is the mode of loaded trucks near the French weight limit (40t, at that time). Then the traffic composition plot in Figure 2 shows that 5-axle trucks are the most frequently trucks observed, and the characteristics of the of trucks affect the load effect on bridges (the tridem is the most important element to take into account).

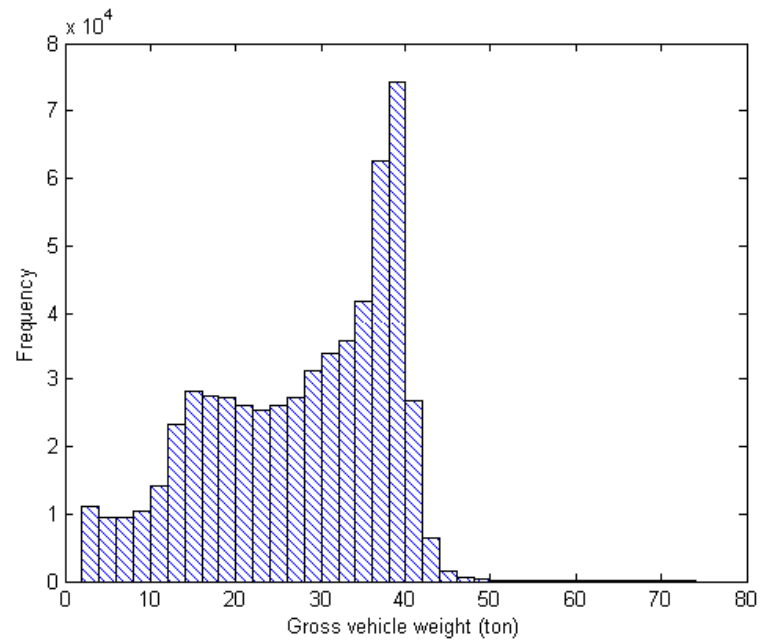

Figure 1 GVW histogram

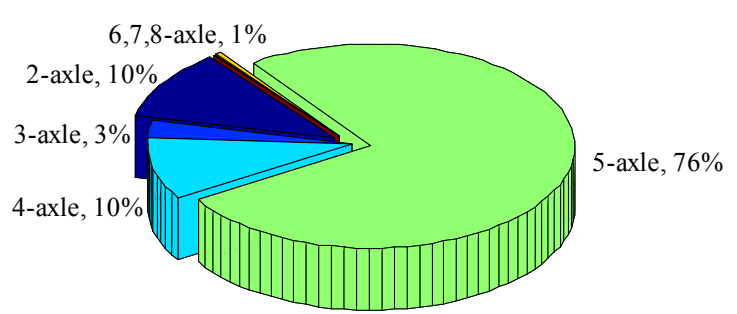

Figure 2 Proportion of vehicle types

To model the annual or even lifetime maximum distribution of the traffic load effects, a large amount of data is required. Although traffic collections from WIM system are of ever increasing quality and reliability, it is still very expensive to collect data during long periods. Although the 86 days validated data are insufficient to assess the characteristic values or extreme value distributions of traffic load effects that are required to evaluate and design bridge structures, they can be used to establish mathematical 
traffic models by using the description of the traffic (traffic composition, the distance between vehicles), and the description of the vehicle (gross vehicle weight, axle weight, spacing between axle, etc). Long term traffic can then be obtained by using Monte Carlo simulation method based on these mathematical models. Using Monte Carlo method to simulate traffic loads or traffic load effects has been demonstrated as an efficient and accurate approach by many authors in recent years (Enright \& O'Brien, 2012). Integrating the Monte Carlo simulated traffic load effects and extreme value modeling method, the maximum distribution of traffic load effect can be established (Zhou, 2013).

\subsection{Methods for modeling the maximum distribution}

The estimation of the distribution of the maximum traffic load effect can be dealt with by extreme value modeling techniques (Castillo et al. 2004). Extreme value theory has demonstrated that the distribution of maxima is asymptotically approximated to the generalized extreme value (GEV) distribution. In practice, these maxima, called block maxima, can be taken out of sample observed in a certain period like a day, or of a certain number of observations. The cumulative distribution function of GEV is then:

$$
G(x ; \xi, \sigma, \mu)=\left\{\begin{array}{rr}
\exp \left\{-\left[1+\xi\left(\frac{x-\mu}{\sigma}\right)\right]^{-1 / \xi}\right\}, & \xi \neq 0 \\
\exp \left[-\exp \left(\frac{x-\mu}{\sigma}\right)\right], & \xi=0
\end{array}\right.
$$

where $\xi, \sigma$, and $\mu$ are the shape, local and scale parameters, respectively.

In practice, we usually just have observations of maxima for short time intervals, but the maximum distribution for long time intervals is required. For instance, an annual maximum distribution of traffic load effects is needed to calculate the annual probability of failure for a bridge, but only a limited number of daily maximum observations were available. To obtain the annual maximum distribution, a GEV distribution is firstly fitted to the daily maxima to obtain the asymptotic daily maximum distribution, $G\left(x ; \xi_{d}, \sigma_{d}, \mu_{d}\right)$, then it is raised to a power according to practical number of days in one year, $n_{d}$, to obtain the annual maximum distribution, $\mathrm{F}_{\max }(\mathrm{x})$. According to extreme value theory, the limit distribution of maxima of a GEV distribution belongs to the GEV maximal domain of attraction, because the Gumbel, Weibull and Fréchet distributions for maxima belongs to themselves maximal domain of attraction (Castillo et al. 2004). Hence, the following equation is derived:

$$
F_{\max }(x)=\left[G\left(x ; \xi_{d}, \sigma_{d}, \mu_{d}\right)\right]^{n_{d}} \approx G\left(x ; \xi_{y}, \sigma_{y}, \mu_{y}\right)
$$

The relation between parameters of daily maximum distribution and annual maximum distribution can be established straightforwardly. If the daily maximum follows a Gumbel distribution as $\xi_{\mathrm{d}}=0$, then the annual maximum corresponds to Gumbel distribution with parameters as follows:

$\sigma_{y}=\sigma_{d}$

$\mu_{y}=\mu_{d}+\sigma_{d} \ln \left(n_{d}\right)$

If the daily maximum follows a Weibull or Fréchet distribution as $\xi_{\mathrm{d}} \neq 0$, then annual maximum follows the Weibull or Frechet distribution, respectively, with parameters as follows:

$\xi_{y}=\xi_{d}$

$\sigma_{y}=\frac{\sigma_{d}}{n^{-\xi_{d}}}$

$\mu_{y}=\mu_{d}+\frac{\sigma_{d}}{\xi_{d}}\left(\frac{1}{n^{-\xi_{d}}}-1\right)$

\subsection{Updating traffic load effect model with consideration of traffic evolution}

\subsubsection{Traffic volume increase}

A crucial assumption in modeling lifetime maximum distribution of traffic load effects for design is the stationarity of traffic. However, the increase of traffic has been widely reported in the literature. Indeed the increase of traffic volume may impact bridges. Gindy \& Nassif (2007) have stated that the traffic volume (or truck volume) has the same significant effect on the frequency of multiple truck presence as bridge span length. The increase of probability of occurrence of multiple-truck-loading event will lead to larger load effects on bridges, and it will threaten the safety of bridges. A linear truck traffic growth model has been widely used to predict future truck traffic ( $\mathrm{Lu}$ et al. 2007). Based on known information, the annual average daily truck traffic at age $t$ can be predicted by:

$$
A A D T T_{t}=A A D T T_{B Y}+A A D T T_{R E F} \cdot G R \cdot\left(t-t_{R E F}\right)
$$

where $G R$ is the traffic growth rate in percentage, $A A D T T_{B Y}$ and $A A D T T_{R E F}$ are the annual average daily truck traffic during the recorded year (used as the basis) and the reference year, respectively. Usually, the base year equals the reference year.

\subsubsection{Traffic composition}

Not only included by the growth of traffic, the propriety of non-stationarity of traffic can arise from the variation of traffic composition. Observations from various countries have demonstrated that the composition of truck traffic has changed dramatically in re- 
cent decades, especially for heavy truck. As shown in Figure 3, the composition of traffic has hugely changed between 1986 and 2010, for traffic measured at two WIM sites in France: the proportion of 5 -axle trucks has increased by about $30 \%$, while the proportion of 4-axle truck has decreased by about $20 \%$. This may be caused by the change in regulations during this period, namely the increase in gross vehicle weight limit from 36 to 40t in 1992. 4-axle tandem trucks were replaced by 5-axle tridem trucks. As a matter of fact, the truck industry always tries to always reach the weight limit of traffic, which may significantly change the vehicle proportions travelling on roads.

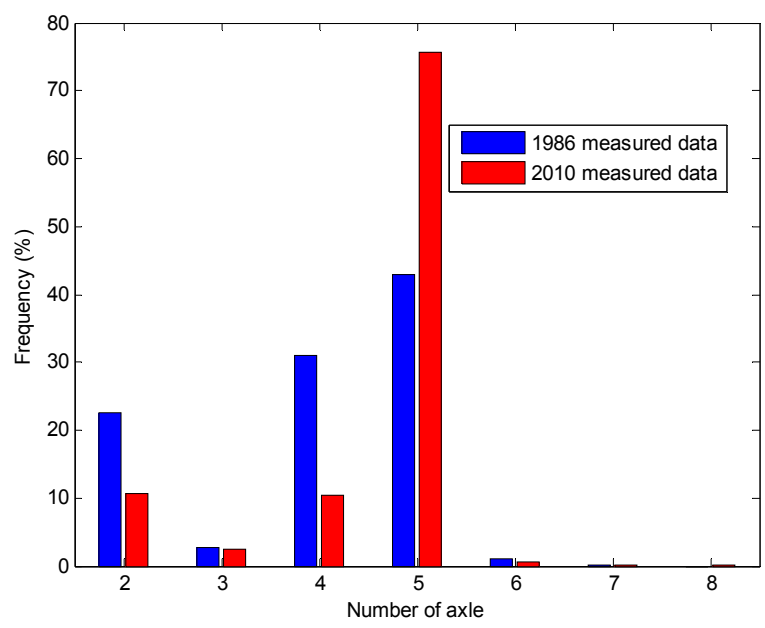

Figure 3 Proportion of vehicle types

\subsubsection{Truck weight limit change}

Due to the limited land resource and traffic safety considerations, the current road network cannot afford continuous increase of traffic volume. If no modal shift is achieved, longer and heavier trucks may be therefore needed to transport freight as it can reduce the traffic volume and also decrease energy consumption (de Ceuster et al. 2008). Allowing these longer and heavier trucks traveling on the road would require to change the current truck weight limit. However, this change in truck weight limit may threaten the safety of existing highway infrastructures like bridges. For instance, Cohen et al. (2003) has reported that an increase in truck weight limit would cause significant life reduction due to fatigue. The truck weight limit change may cause a series of changes including GVW, axle weight, traffic composition, and also leads to introduce new types of trucks.

Many different approaches have been developed to predict such changes in distribution of truck weights. In this paper, the method which predicts the distribution through the histogram of measured truck weights, developed by Cohen et al. (2003) has been adopted. Their approach considers changes in the truck weight histogram due to three types of freight shifting: the truck load shift without change in truck types, the truck load shift with a change of truck configuration, and the exogenous shift from e.g. economy growth. In this study, only the first type of freight shifting has been considered, because a potential proposal of change in the weight limit is to allow a 5-axle truck load 44 tons maximum against current 40 tons in France(General Council of Environment and Sustainable Development, 2011).

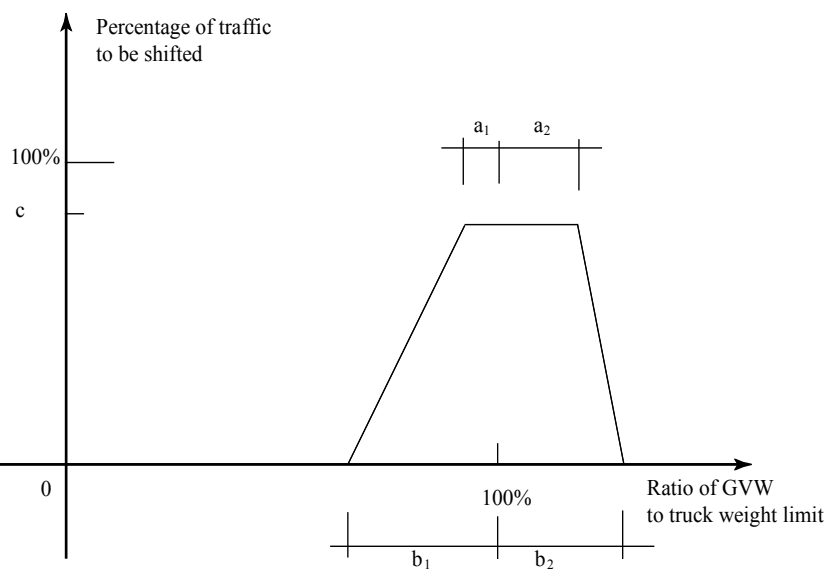

Figure 4. Window for truck traffic shifting (following Cohen et al. (2003))

In modeling the truck load shift, it is assumed that the shifting occurs only to truck traffic that is potentially sensitive to the weight limit change. This truck traffic reacting to the change of weight limit is determined using a trapezoid window shown in Figure 4. The abscissa is the ratio, $\gamma$, of GVW to permitted maximum gross vehicle weight (PMGVW), the vertical axis the percentage of traffic to be shifted. The window is defined using four values of ratio $\gamma: a_{l}$, $a_{2}, b_{1}$, and $b_{2}$, and $c$ for the traffic amount to be shifted in percentage. In the following, BC refers to the base case before the implementation of truck weight limit change, and AS refers to the alternative scenario after the change. According to the defined rule, $c$ the percentage of traffic with ratio $\gamma$ will change their weight to $\mathrm{GVW}_{\mathrm{AS}}$ as the weight limit is modified. The percentage of traffic linearly varies from $c$ to zero in the ranges $\left[1-b_{1}, 1-a_{1}\right]$ and $\left[1+a_{2}\right.$, $\left.1+b_{2}\right]$. No traffic changes to the change beyond the range defined by the window are assumed. The weight of the modified truck traffic, $\Delta T T_{G V W k, B C}$, for each weight interval in the histogram can therefore be formulated as:

$$
\Delta T T_{G V W_{k, B C}}= \begin{cases}c T T_{k, B C} \frac{\left(\gamma-1+b_{1}\right)}{\left(b_{1}-a_{2}\right)}, & 1-b_{1}<\gamma<1-a_{1} \\ c T T_{k, B C}, & 1-a_{1}<\gamma<1+a_{2} \\ c T T_{k, B C} \frac{\left(1+b_{2}-\gamma\right)}{\left(b_{2}-a_{2}\right)}, & 1+a_{2}<\gamma<1+\mathrm{b}_{2} \\ 0, & \text { otherwise }\end{cases}
$$

Where $T T_{k, B C}$ is the truck traffic in the $k^{\text {th }}$ interval in the truck weight histogram under base case. The 
$\Delta T T_{G V W k, B C}$ will shift to $j^{\text {th }}$ interval with midpoint value of

$G V W_{j, A S}=G V W_{k, B C}\left(\frac{P M G V W_{A S}}{P M G V W_{B C}}\right)$

The total volume of freight is assumed to be the same before and after executing the weight limit change. There is thus the need to adjust the weight of the changed truck traffic to meet this assumption. Moreover, the increasing of truck weight limit may lead to change tare weight from $T A R E_{B C}$ to $T A R E_{A S}$, as the trucks need to increase their loading capacity through extending the vehicle length or ameliorating the engine. This change of traffic is determined through:

$$
\Delta T T_{G V W_{j, A S}}=\frac{\Delta T T_{G V W_{k, B C}}\left(G V W_{k, B C}-T A R E_{B C}\right)}{G V W_{j, A S}-T A R E_{A S}}
$$

The value of $G V W_{j, A S}$ may not exactly match the $j^{\text {th }}$ interval in the histogram. The $\triangle T T_{G V W j, A S}$ truck weights should be distributed to two neighboring intervals, $i^{\text {th }}$ and $i+I^{\text {th }}$, to achieve the desired value of $G V W_{j, A S}$. The amount of truck weights in percentages, $p_{i}$ and $p_{i+1}$ that are distributed to these two intervals are determined by:

$$
\begin{aligned}
& p_{i}+p_{i+1}=1 \\
& p_{i} G V W_{i, A S}+p_{i+1} G V W_{i+1, A S}=G V W_{j, A S}
\end{aligned}
$$

\section{APPLICATION}

\subsection{Structural configuration}

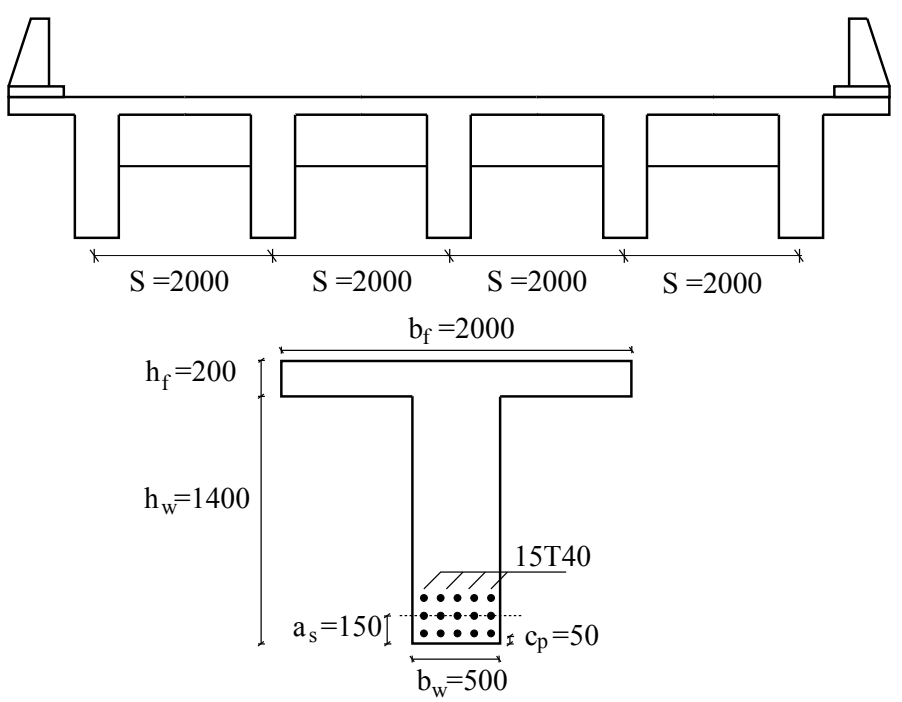

Figure 5. Cross-section of transverse bridge and T-beam

A simply supported reinforced concrete (RC) bridge has been considered for illustrating application of the methods presented. The bridge consisting of 5 $\mathrm{RC}$ beams is $30 \mathrm{~m}$ in span length and carries two traffic lanes with an $11 \mathrm{~m}$ wide deck as shown in
Figure 5. It was designed according to the Eurocode 2 (CEN, 2005) using the Eurocode Load Model 1 (CEN, 2003).

The nominal bending moment, $\mathrm{M}_{\mathrm{R}}$, can be determined using Eurocode 2. When the compression flange thickness is equal or greater than the depth of the equivalent rectangular stress, $M_{R}$ should be computed as:

$M_{R}=0.95 f_{y} A_{s}\left[h_{f}+h_{w}-\alpha_{s}-0.4 x\right]$

Where $A_{S}$ is area of longitudinal reinforcing steel, $f_{y}$ is the yield strength of reinforcing steel, $h_{f}$ is the height of the flange, $h_{w}$ is the height of the webs, $\alpha_{s}$ is the distance between the gravity center of the reinforcing steel in tension to the bottom fiber, $x$ is the depth of the equivalent rectangular stress block.

If the compression stress block extends to the web, then $M_{R}$ should be expressed as:

$$
\begin{aligned}
M_{R}= & A_{s} f_{y}\left[h_{f}+h_{w}-\alpha_{s}-0.4 x\right] \\
& +0.459 f_{c} h_{f}\left(b_{f}-b_{w}\right)\left(0.4 x-0.5 h_{f}\right)
\end{aligned}
$$

Where $b_{f}$ is width and thickness of the flange, $b_{w}$ is the width of the webs, and $f_{c}$ is the compressive strength of the concrete at 28 days. The statistical parameters for these dimensions, material properties for this RC bridge are given in Table 1 as been used by de Cássia Silva \& Cremona (2005).

Table 1. Probabilistic descriptions of the main stochastic variables for the bridge.

\begin{tabular}{llll}
\hline Notation & Distribution & Mean & Std or COV \\
\hline $\mathrm{f}_{\mathrm{y}}\left(\mathrm{N} / \mathrm{mm}^{2}\right)$ & Lognormal & 1.25 & 0.08 \\
$\mathrm{f}_{\mathrm{cu}}\left(\mathrm{N} / \mathrm{mm}^{2}\right)$ & Lognormal & 1.28 & 0.11 \\
$\mathrm{~d}_{0}(\mathrm{~mm})$ & Normal & 1.0 & 0.04 \\
$\rho_{\mathrm{c}}\left(\mathrm{kg} / \mathrm{m}^{3}\right)$ & Normal & 1.07 & 0.10 \\
\hline
\end{tabular}

\subsection{Results of reliability analysis}

The safety margin is formulated in terms of bending moment, and the limit state function of the girder is:

$g=M_{R}-M_{D D}-M_{L L}$

where $M_{D D}$ is the dead load effect, and $M_{L L}$ is the traffic load induced moment on the girder.

Table 2. Statistic characteristics of the variables

\begin{tabular}{llll}
\hline Notation & Distribution & Mean & COV \\
\hline $\mathrm{Ccr},(\mathrm{kg} / \mathrm{m} 3)$ & Lognormal & 3.0 & 0.19 \\
$\mathrm{Cs},(\mathrm{kg} / \mathrm{m} 3)$ & Lognormal & 3.3 & 0.5 \\
$\mathrm{D},(10-12 \mathrm{~m} 2 / \mathrm{s})$ & Lognormal & 2.0 & 0.75 \\
$\mathrm{R}$ & Normal & 1 & 0.75 \\
$\mathrm{i}_{\text {corr }}\left(\mu \mathrm{A} / \mathrm{cm}^{2}\right)$ & Normal & 3 & 0.33 \\
$\mathrm{cp},(\mathrm{mm})$ & Normal & 50 & 0.13 \\
\hline
\end{tabular}

Table 2 presents a summary of the data used in the reliability analysis in order to consider the degradation of resistance, $M_{R}$. These statistical parameters have been used previously by de Cássia Silva \& Cremona, (2005). Basing on 2000 days simulation 
traffic, the traffic load effect, $M_{L L}$, has been obtained by the method described in Section 4 , and a dynamic amplification factor following a normal distribution with mean value 1.12 and variation of 0.71 has been considered.

\subsubsection{Growth of traffic volume}

For the purpose of illustrating the influence of traffic growth, an increase in the annual average daily truck traffic (AADTT) by $10 \%, 20 \%, 30 \%$ and $40 \%$ was simulated, but the traffic composition unchanged was kept. It resulted in the change in the annual maximum distribution of traffic load effect as illustrated in Figure 6: it should be noticed that the mode of annual maximum distribution for traffic with unchanged traffic volume is the smallest, but the mode for traffic with an increase of $30 \%$ has generated the largest mode of this annual maximum distribution. Hence, it can be stated that the increase of traffic volume will generate larger traffic but the increment remains small.

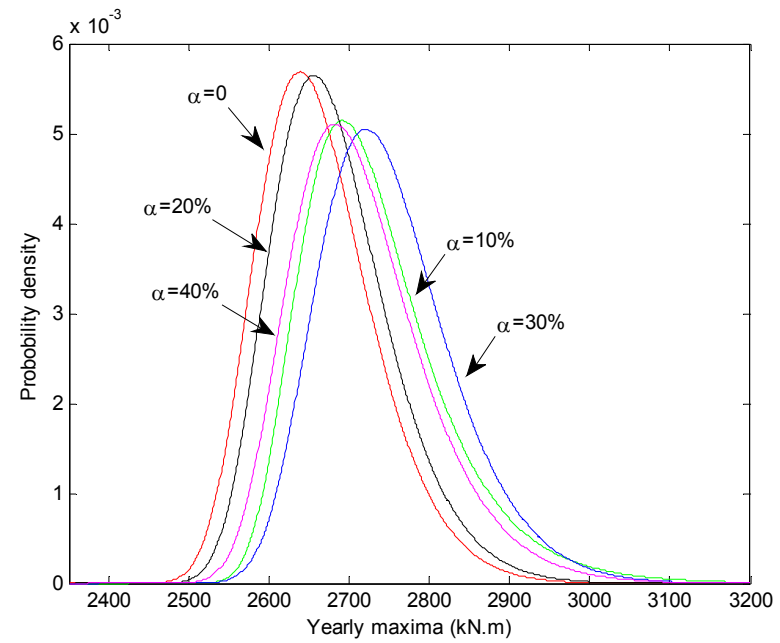

Figure 6. Comparison of annual maximum distribution of traffic load effect under different assumptions of growth ratio of traffic volume.

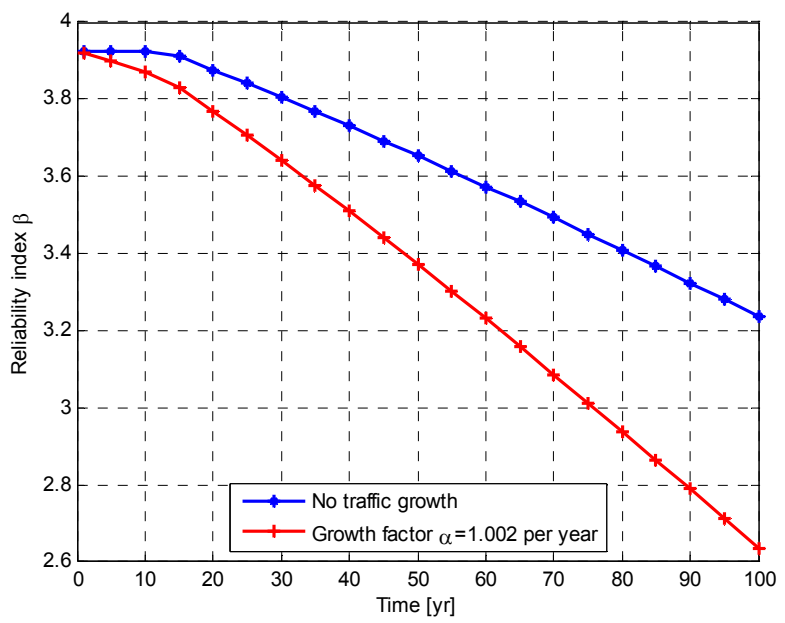

Figure 7. Influence of traffic growth on structural resistance

According to this statistical analysis on traffic load effect and the expected $1.7 \%$ average annual growth rate of road freight in Europe, we assume that the mean value of traffic load effect will have a $0.2 \%$ per year growth for the following analysis. It can lead to a total increment of about $20 \%$ in 100 years of design lifetime for bridge designed according to Eurocode. The result of time-dependent annual probability of failure is then given in Figure 7. The reliability index for traffic condition with consideration of traffic growth decreases quicker than that without traffic growth.

\subsubsection{Traffic composition}

In this section, the investigations on the effect of variation of traffic composition are presented. We assume that the cause of change in traffic composition is to transport more goods, and therefore the increase of traffic is actually by reducing the volume of lighter load trucks. In addition, we assume that the change of traffic composition takes place when the traffic volume has already increased by $20 \%$. Two traffic composition change scenarios have been considered in this study. The first one is to simulate an increase in the proportion of 5-axle trucks by $10 \%$ while the proportions of the 6- and more-axle trucks keep unchanged. The other one is to assume an increase of $10 \%$ in the proportion of 6-axle trucks with reducing the proportion of 4- and less axle trucks but keeping the proportions of 5-, 7- and 8axle trucks unchanged. In both cases, the total flow is unchanged, and only the distribution of vehicle types is changed.

The annual maximum distributions of traffic load effects induced by the two considered traffic scenarios are shown in Figure 8. The distribution from measured traffic is given also as a reference. The comparison shows that the traffic load effect is insensitive to the increase of 5-axle trucks proportion. It may not be surprising as the maxima are mainly governed by single truck loading events and the increase in the proportion of 5-axle actually do not increase the potential maxima of load effect. In contrast, the distribution is significantly shifted to the left when increasing the proportion of 6-axle trucks.

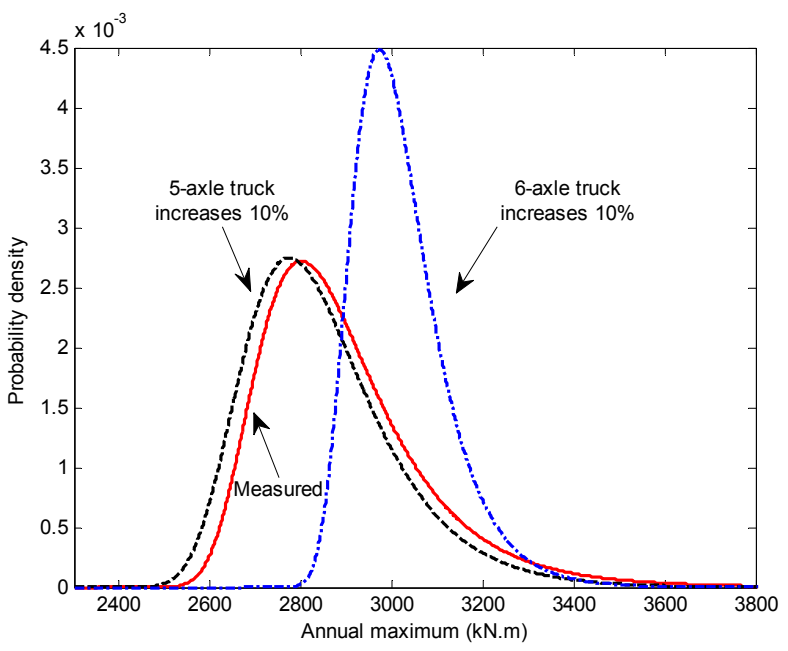

Figure 8. Comparison of annual maximum distribution of traffic load effect under different traffic compositions. 
A comparison of reliability analysis results is presented in Figure 9. It is found that a growth of $10 \%$ in the proportion of 5-axle trucks lessens approximately $2 \%$ the reliability index, and a growth of $10 \%$ in the proportion of 6 -axle trucks lessens approximately $5 \%$. Hence, the growth in the proportion of heavy trucks in the flow has a small influence for the safety of bridge under current weight limit regulations.

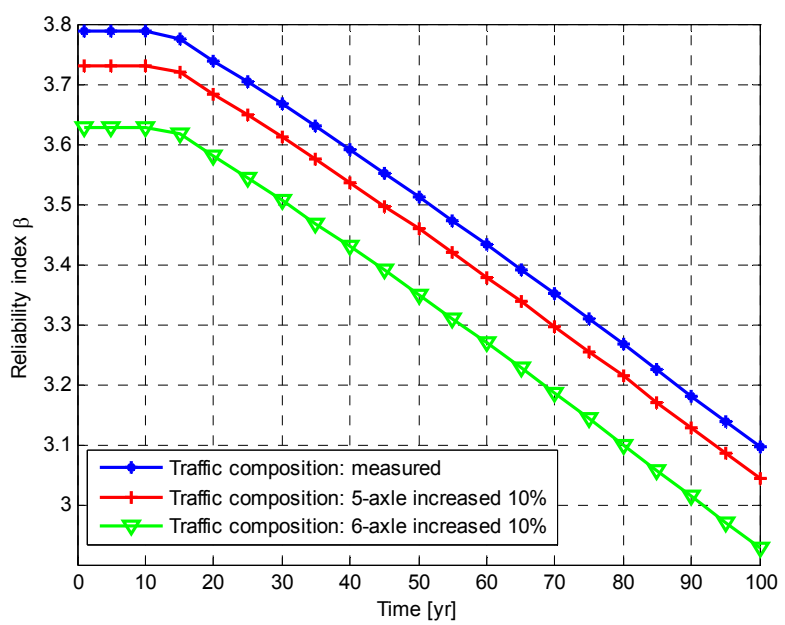

Figure 9. Comparison of updated annual reliability indices.

\subsubsection{Change in the weight limit}

The weight limits in France may increase from current 40 tons to 44 tons with further conditions (Decree No. 2012-1359, 2012). 5-axle trucks and especially the truck category of T2S3 (Tractor with 2 axles and Semi-trailer with 3 axles) may strongly react to this change because of the following reasons: (1) The majority of trucks traveling in the French road network are 5-axle trucks (see Figure 2 ), and T2S3 trucks take around 95\% in this truckgroup. (2) The trucks weighted around the actual weight limit are of this type. Hence, only the change in the GVW of 5-axle trucks of T2S3 category is considered in this section.

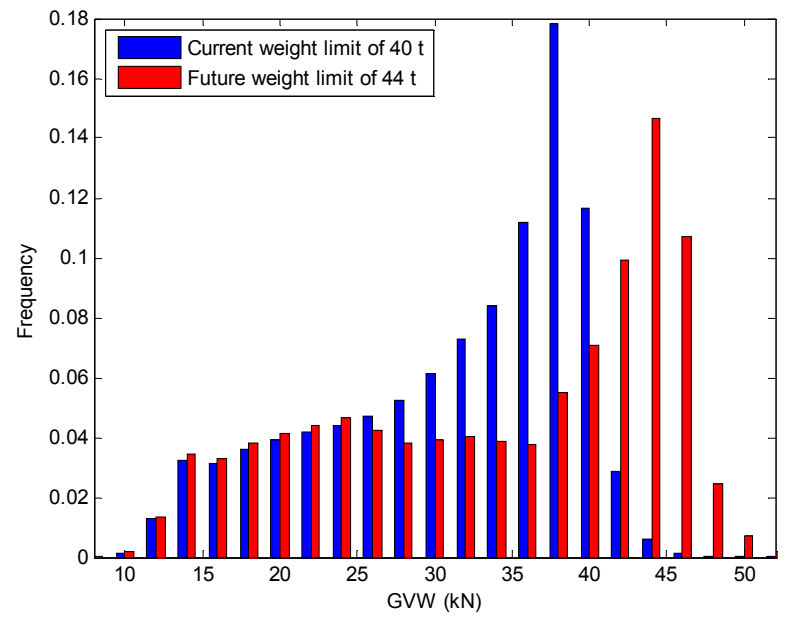

Figure 10. Comparison of 5-axle truck GVW histogram under current and future weight limit.

The window parameters recommended by Cohen et al. (2003) have been used: $a_{1}=a_{2}=10 \%$, $b_{1}=b_{2}=20 \%$, and $c=95 \%$. Figure 10 shows the comparison of the predicted truck weight histogram and the refer one. As expected, the peak shifts from around 40 tons to around 44 tons which is the new truck weight limit. Consequently, the annual maximum distribution of traffic shifts also as shown in Figure 11. Figure 12 illustrates the comparison of the resulting reliability index for the deteriorating reinforced concrete bridge assessment. The difference in reliability is clearly shown by Figure 12, and it decreases about $10 \%$ from 3.92 to 3.53 due to this increasing truck weight limit. It clearly indicates that an intervention operation should be taken advance for deteriorated bridges if a new weight limit regulation is implemented.

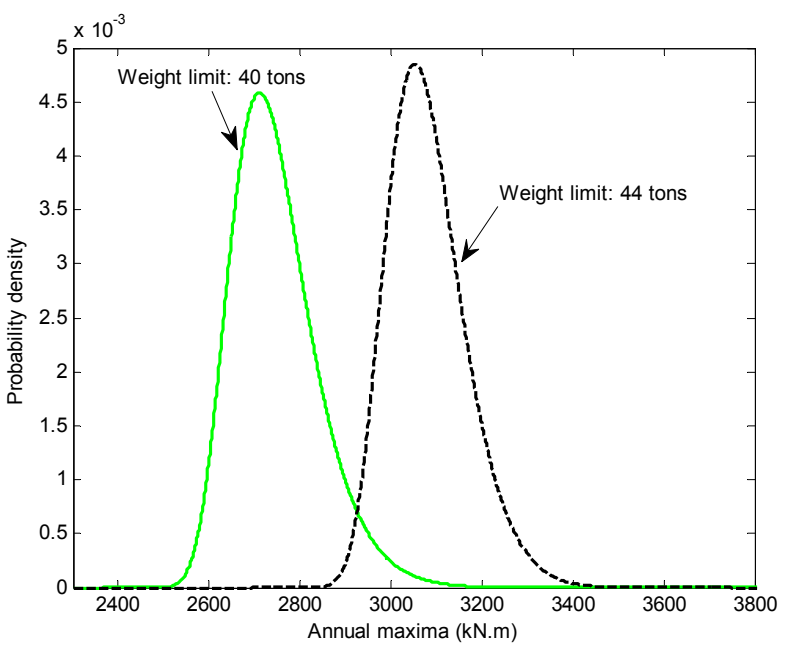

Figure 11. Comparison of annual maximum distribution of traffic load effect for weight limits of $40 \mathrm{t}$ and $44 \mathrm{t}$.

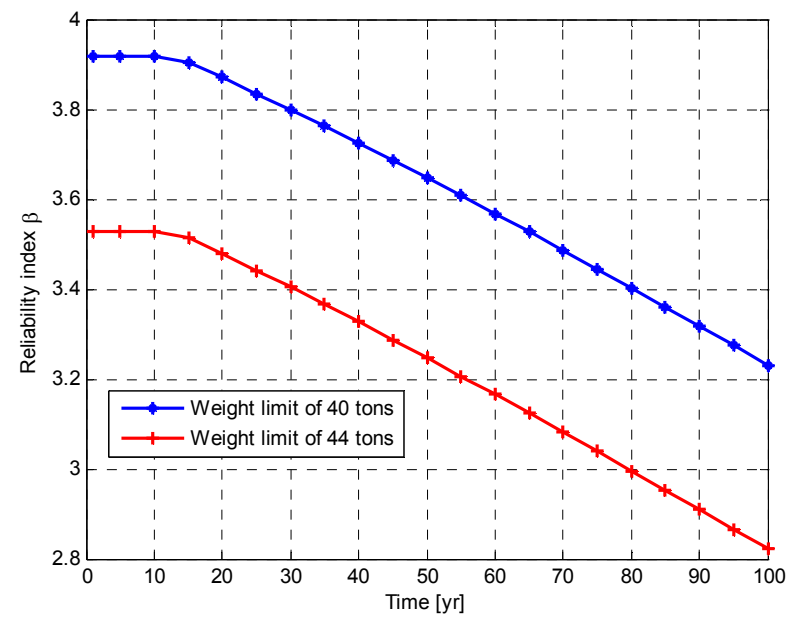

Figure 12. Comparison of updated annual reliability indices.

\section{CONCLUSIONS}

This paper has been presented an application of WIM data to perform a reliability based assessment of a RC bridge structure. Besides using a commonly used reinforcement area loss model to consider the degradation of resistance along the service time due to chloride induced corrosion, a considerable attention is paid on establishing the annual maximum dis- 
tribution of traffic load effects with consideration of traffic evolution. Traffic evolution may arise from a growth of average daily truck traffic, a growth in the proportion of heavy trucks due to the demand of increased volume of freight transportation, and an introduction of a new regulation on weight limit. From the results obtained in an application to a reinforced concrete bridge, the major influence on the reliability comes from a possible change in permitted maximum gross vehicle weight. On the other hand, increases of daily traffic volume or increases the proportion of heavy vehicle in the flow have a much less significant influence.

\section{ACKNOLEDGMENTS}

The authors greatly acknowledge the financial support provided by the Marie Curie Initial Training Network TEAM (Training in European Asset Management) project.

\section{REFERENCES}

Bailey, S., \& Bez, R. 1999. Site specific probability distribution of extreme traffic action effects. Probabilistic Engineering Mechanics, 14(1-2):19-26.

Bakht, B., \& Jaeger, L. G. Multi-presence reduction factors for bridges. Proc. Bridge and trasmission line structures, ASCE Structures Congress, 17-20.

de Cássia Silva, R., \& Cremona, C. 2005. Some considerations on the performance cycle analysis of concrete girders in France. Structure and Infrastructure Engineering, 1(3): 207220.

Castillo, E., Hadi, A. S., Balakrishnan, N., \& Sarabia, J. M. 2004. Extreme Value and Related Models with Applications in Engineering and Science. Wiley Series in Probability and Statistics, Wiley.

CEN 2003. Eurocode 1: Actions on structures - Part 2: Traffic loads on bridges, EN 1991-2. European Committee for Standardization, Brussels.

CEN 2005. Eurocode 2 - Design of concrete structures - Concrete bridges - Design and detailing rules, European Standard EN 1992-2. European Committee for Standardization, Brussels.

de Ceuster, G., Breemersch, T., van Herbruggen, B., Verweij, K., Davydenko, I., Klingender, M., Jacob, B., Arki, H., \& Bereni, M. 2008. Effects of adapting the rules on weights and dimensions of heavy commercial vehicles as established within Directive 96/53/EC. Brussels, Belgium.

Cohen, H., Fu, G., Dekelbab, W., \& Moses, F. 2003. Predicting Truck Load Spectra under Weight Limit Changes and Its Application to Steel Bridge Fatigue Assessment. Journal of Bridge Engineering, 8(5): 312-322.

Cremona, C. 2011. The surveillance of bridges in France. Proc. 6th International Conference on Acoustical and Vibratory Surveillance Methods and Diagnostic TechniquesParis, France, 1-17.

Decree No. 2012-1359. 2012. Decree No. 2012-1359 of 4 December 2012 on the total weight permitted for land motor vehicles.

$<$ http://www.legifrance.gouv.fr/affichTexte.do?cidTexte $=$ J ORTEXT000026729044\&dateTexte $=\&$ categorieLien $=\mathrm{id}>$.
Du, Y., Cullen, M., and Li, C. 2013. Structural performance of $\mathrm{RC}$ beams under simultaneous loading and reinforcement corrosion. Construction and Building Materials, 38(0): 472-481.

Enright, B., \& O'Brien, E. J. 2012. Monte Carlo simulation of extreme traffic loading on short and medium span bridges. Structure and Infrastructure Engineering, 1-16.

European Commission 2012. EU Transport in Figures: Statistical Pocketbook, Publications Office of the European Union, Luxembourg.

European Commission 2008. European energy and transport: trends to 2030 - updated 2007, Luxembourg: Office for Official Publications of the European Communities, Belgium.

Flint, A., \& Jacob, B. 1996. Extreme traffic loads on road bridges and target values of their effects for code calibration. Proc. IABSE Colloquium Basis of Design and Actions on StructuresDeflt, 469-477.

General Council of Environment \& Sustainable Development 2011. Report to parliament on the issues and impacts related to the generalization of the authorization of circulation of 44 tons trucks. Ministry of Ecology, Energy, Sustainable Development and Sea, France.

Gindy, M., \& Nassif, H. 2007. Multiple Presence Statistics for Bridge Live Load Based on Weigh-in-Motion Data. Transportation Research Record: Journal of the Transportation Research Board, 2028:125-135.

Jacob, B., Maillard, J., \& Gorse, J. 1989. Probabilistic Traffic Load Models and Extreme Loads on a Bridge. Proc. 5th International Conference on Structural Safety and Reliability, 1973-1980.

Lu, Q., Zhang, Y., \& Harvey, J. T. 2007. Analysis of truck traffic growth for the mechanistic empirical pavement design guide. Proc. TRB 2007 Annual Meeting, Transport Research Board, Washington D. C.

Melchers, R. E. 1987. Structural reliability: Analysis and Prediction, Ellis horwood limited, England.

Stewart, M. G., \& Rosowsky, D. V. 1998. Time-dependent reliability of deteriorating reinforced concrete bridge decks. Structural Safety, 20(1): 91-109.

Weyers, R. E., Fitch, M. G., Larsen, E. P., \& Al-Qadi, I. L. 1994. Concrete bridge protection and rehabilitation: Chemical and physical techniques. National Research Council, Washington D. C.

Zhou, X. 2013. Statistical analysis of traffic loads and their effects on bridges. Docteroral thesis, École doctorale sciences ingénierie et environnement, Université Paris-Est, Paris, France. 